unreifen Mohnsamenkapseln ein Extract bereitet; dieses Extract hat einen überaus starken betäubenden Geruch, und ist wahrscheinlich von grofser Wirksamkeit, was auszumitteln - wir aber den Aerzten überlassen müssen.

\title{
Ueber die Darstellung der narkotischen Extracte;
}

\section{von \\ Rudolph Brandes.}

Die Darstellung guter narkotischer Extracte ist eine Hauptaufgabe der pharmaceutischen Praxis. Die Bemerkungen, welche Fr. Bucholz in Erfurt darüber mitgetheilt hat *), verdienen die sorgfalltigste Beachtung. Diese betreffen vorzüglich die Einengung der Auszüge zur Extractconsistenz, and ob dabei das Wasserbad oder Dampfbad vorzuziehen sei. Buch ol z entscheidet sich für das Wasserbad, und wer die Resultate beider Methoden vergleichend geprüft hat, wird unbedingt ihm beistimmen, besonders wenn die Einwirkung des Dampfs gegen Ende der Arbeit noch mit einer Spannung desselben statt findet, wo die oberen freien Wände des Abdampfungssgefäfses so heifs werden, dafs die sich daran hinaufziehende Flüssigkeit eintrocknet und der Wärme ferner ausgesetzt, der eingetrocknete Theil zu einem halbkarbonisirten und also zersetzten Körper einschrumpft. Selbst die Temperatur des siedenden Wassers ist zu grofs, wenn sie bis zu den letzten Stadien der Concentration erhalten wird. Jahn in Meiningen und W. B u cholz in Gotha haben kürzlich eben so sehr zu be-

*) S. diesc Zeitschr. 2 R. XI, 234. 
herzigende Beobachtungen über die Darstellung der narkotischen Extracte mitgetheilt, die zum Theil auch auf diesen Punct hinausgehen*).

Wie dem auch sei, alle Erfahrungen stimmen darin überein, dafs die Enengung der Auszüge in möglichst geringer Wärme statt finde; und vor geraumer Zeit habe ich gezeigt, dafs die wirksamen Bestandtheile der narkotischen Pflanzen in den Verbindungen, in welchen sie in den Gewächsen enthalten sind, in Weingeist sich. leicht lösen, während eine Menge anderer Stoffe derselben, die nur in Wasser löslich sind, nicht vom Weingeist anfgenommen werden, die durch Weingeist bereiteten Auszüge daher die wirksamen Bestandtheile in concentrirterer Form enthalten, folglich wirksainer sind, und auch gleichförmiger, weil wenigstens die Zufälligkeiten, die den Gehalt der nur in Wasser löslichen Bestandtheile treffen, ausgemerzt sind **).

Bei der Bereitung der narkotischen Extracte sind daher zwei Hauptpuncte ins Auge zu fassen: 1) die Flüssigkeit, mit welcher der Auszug bereitet wird, und 2) die Temperatur, welche man zur Concentration anwendet.

Entsprechen die neuen Vorschriften, welche zum Theil auf diese Sätze gegründet sind, diesen Anforderungen völlig? Ich glaube nicht.

Die Preufs. Pharmakopie (sowie die, welche derselben gefolgt sind), giebt die Bereitung aus frischem und getrocknetem Kraut zu. Sind die Kräuter vorsichtig getrocknet und sorgfältig gegen Luft und Licht anfbewahrt, die Pulver in zuvor erwärmten und fest ver-

*) S. diese Zeitschr. 2. R. XVII, 97.

**) Vergl. meine ersten Mittheilungen über diesen Gegenstand in 1. Bde. 1. R. S. 189 dieses Arcbivs, 1822. 
schlossenen, nicht zu grofsen Gläsern, so ist mit denselben das trefflichste Extract darzustellen.

Bei der Darstellung der narkotischen Extracte aus trocknem Kraut soll nach der Vorschrift 1 Pfd. desselben mit 5 Pfunden rectificirtem Weingeist 36 - 48 Stunden digeriren, und dann die Flüssiglieit durch Auspressen u. s. w. gesondert werden. Der Krautriickstand wird darauf mit 10 Pfunden heifsem Wasser übergossen, bleibt damit 24-48 Stunden stehen, worauf die Flüssigkeit ebenfalls durch Auspressen gesondert wird. Diese Flüssigkeit soll bis auf $\frac{1}{3}$ Rückstand abgedampft und dieser init rectificirtem Weingeist so lange vermischt werden, bis keine Trübung mehr entsteht. Angenommen, dafs man den wässrigen Auszug bis zu 3 Pfd. abgedampft habe, so wird man wenigstens auch 3 Pfd. Weingeist zusetzen müssen. Nach der Fällung wird filtrirt und das Filtrat darauf mit dem ersten weingeistigen Auszuge vermischt, der Spiritus abdestillirt und der Rückstand im Dampfbade zur vorschriftsmäfsigen Consistenz eingeengt.

Unterwerfen wir diese Methode, unter Zugrundelegung neuerer Erfahrungen, einer sorgsamen Kritil, so tinden wir, dafs dieselbe eine grofse Menge Flüssigkeit erfordert, auf 1 Pfd. $5+3$ l'fd. Spiritus und 10 Pfd. Wasser, also 18 Pfd. Flüssiglieit, womit das Kraut 3-4 Tage in Digerirtemperatur bleibt, endlich erfordert diese Flüssigkeit noch eine geraume Zeit zur Verdampfung, um bis zur Extractconsistenz, also bis auf $2-3$ Unzen, welches ohngefähr die Ausbeute an Extract aus cinem l'funde der narkotischen Kräuter ist, einzuengen, und auch während dieser Zeit ist sie der Einwirkung einer hohen Temperatur anşesetzt. Wenn die wirksamen Bestaudheile durch Weingeist den in Rede stehenden 
Pflanzen entzogen werden, so ist nicht wohl abzusehen, warum die "weite Ausziehung mil Wasser gemacht werden soll, dessen Verdampfung wicder eine höhere und länger dauernde Wärme erfordert.

Bei der Darstellung der narkotischen Exiracte aus frischen Kräutern, wird der Saft derselben ausgeprefst, aufgekocht, abgeschäumt und im Dampfbade zur Honigdicke verdampft. Das Satzmehl mit dem ausgeprefsten Kautrückstande wird jetzt mit scinem doppclten Gewicht Alkohol 24 Stunden lang digerirt, ausgepre`st, die Flüssigkeit bis zur Hälfte abdestillirt, bis zur Honigdicke verdampft, mit dem eben so weit eingedickten Safte vermischt, und dann das Ganze bis zur Pillenconsistenz. verdampft.

Unterwerfen wir anch diese Methode einer nähern Betrachtung, so sehen wir, dafs gegen die erste hier keine Ausziehung mit Wasser angewandt wird, was gewifs angemessen ist, aber billig fragen wir: Warum schreibt die Pharmakopüe bei der einen Methode Alkohol, bei der andern rectificirten Weingeist vor? Warum werden nach der einen Methode die nur in Wasser löslichen und indifferenten Storfe durch Weingeist abgeschieden, nach der andern aber nicht? Beide Methoden würden in einer angemessenen Uebereinstimmung sein, wenn auch der Rückstand des Krautes nach Auspressen des Saftes mit rectificirtem Veingeist behandelt, und mit diesem Auszuge der durch Einengen concentrirte Saft versetzt würde, worauf man colirte und das Ganze zur vorschriftsmäfsigen Consistenz brächte.

Nach dieser Auseinandersetzung scheint es mir erwiesen, dafs die Darstellung der narkotischen Extracte noch mehrer Verbesserungen bedarf, die aber wesentlich von den beiden oben aufgestellten Principien ausgehen 
müssen. Auf diese gestützt, lege ich folgendes Verfahren vor, was ich schon mehrmals früher versucht habe, worüber ich aber seit einigen Jahren gelegentlich besondere Versuche in meinem Laboratorio anstellen liefs, um die für eine allgemeine Angabe nöthigen Details aus mehren Operationen abznleiten.

\section{Methode.}

1 Pfd. (16 Unzen) des gröblich gepülverten Krautes wird in einen Deplacirungscylinder eingedrückt, aber nicht zu fest, und dann mit Spiritus von 65 bis $70 \%$ übergossen. Das Pulver befindet sich in dem Cylinder bekanntlich zwischen zwei kleinen Blechsieben, auf das unterste befestigt man zugleich eine Scheibe Filtrirpapier. Der Spiritus wird anfangs eingesogen, ohne dafs etwas abtröpfelt, man giefst fortwährend nach. Endlich tröpfelt unten die Flüssigkeit ab, und zwar sehr concentrirt und intensiv dunkelgrün gefärbt, man giefst so lange Spiritus in den Cylinder nach, bis 90 Unzen aufgegeben sind, und hört dann auf. Man kann der Erschöpfung gewirs sein, denn die zuletzt abtröpfelnde Flüssigkeit hinterläfst beim Verdunsten nur noch wenig Extract, die Unze kaum 3 Gran. Wenn das Abtröpfeln aus dem $C y$ linder aufhört, giefst man Wasser hinein, um durch dasselbe den noch in dem Kraute steckenden Spiritus, 10 - 11 Unzen, auszutreiben; man läfst abtröpfeln, bis man 90 Unzen Flüssigkeit wieder erhalten hat, oder bis die nach dem Aufgiefsen des Wassers anfangs wenig gefärbt abtröpfelnde Flüssigkeit wieder eine dunklere braune Farbe annimmt, ein Zeichen, dafs der noch zurückgebliebene Spiritus wenigstens grörstentheils entfernt ist, und nun der wässrige Auszug kümmt, der nicht in das Extract darf. 
Die säunmtichen geistigen Auszüge giefst man in -eine Porcellanschale und stellt diese in die Destillirblase des Beindorf'schen Apparats, und destillirt allen Spiritus ab. Die Schale wird dann herausgenommen und enthält die Extractflüssigkeit, worin das Chlorophyll in Häuten und Körnern abgeschieden ist. Ich halte nicht dăfïr, dieses bei dem Extract zu lassen, soll es geschehen, so mufs es nun durch anhaltendes Rühren innig damit wieder vermengt werden. Consequent aber den aufgestellten Principien wird die Fliissigkeit jetzt filtrirt. Sie hat einen äufserst intensiven fast unerträglichen narkotischen Geruch, den sie bei dem weiteren Abdampfen »u einem grofsen Theil einbü fst. Die grünharzige Masse, welche auf dem Filter verbleibt, beträgt 4-5 Drachmen. Die Extractflüssigkeit wird endlich in einer kleinen Porcellanschale im Wasserbade bei $50-60^{\circ} \mathrm{R}$. g.ur vorschriftsmäfsigen Consistenz gebracht.

Bei der näheren Betrachtung dieser Methode stellen sich nun folgende Vorzüge derselben heraus. Der ganze Verlauf der Darstellung des Auszuges des narkotischen Vegetabils findet, ohne alle von aufsen angebrachteWarme, bei der gewölnnlichen Temperatur statt. Das Durchtrüpfeln der Flüssigkeit erfurdert gegen 3-4 Tage. Nach der Vorschrift der Pharmakopöe ist das Kraut eine eben so lange Zeit einer Digerirtemperatur ausgesetzt.

Nach unserer Methode wird 1 Pfd. Krant durch 90 Unzen Spiritus völlig erschöpft, und also durch eine Flüssigkeit, die keine 2 Pfd. Wasser enthält, während nach der Pharmakopöe auf dieselbe Krautmenge 8 pfd. Spiritus (128 Unzen) und 10 Pfd. Wasser genommen werden müssen.

Nach der Pharmakopöe ist nicht nur eine über 
viernal so grofse Menge Flüssigkeit zu verdampfen als nach unserer Methode, sondern diese Flüssigkeit besteht dazu noch über die Hälfte aus Wasser, und bedarf daher der Auszug, nach der Pharmakopïe bereitet, eine viermal längere Zeit und eine gröfsere Würme, um zu der vorschriftmäfsigen Consistenz gebracht zu werden, als der nach anserer Methode dargestellte Auszug erfordert, nach welcher dazu noch der grö̈seste Theil verdunstet wird, mittelst der angegebenen Abdestillirung des Spiritus, ohne dals dic Luft Zutritt hat; also nicht verändernd darauf wirlien kann, und nur ein kleiner Theil Fliissigkeit noch im $W$ asserbade in der offenen Porzellanschale zum Verdunsten übrig bleibt.

Nach der Art, wie wir die Abdestillirung des Spiritus bewirken, ist endlich auch der Uebelstand gänzlich beseitigt, dafs an einzelnen Stellen der Gefufswäinde eingetrocknetne Extractbrühe durch größsere Hitze mehr oder weniger verkohlt werde.

Dals sich die nach unserer Methode erhaltenen und vom Spiritus durch Abdestilliren befreiten Extractflüssigkeiten endlich durch künstliche Austrocknungsmittel, mittelst luftverduinntem Raum, durch Chlorcalcium u. s. w., noch durch weniger $W$ ärme concentriren lassen, versteht sich von selbst. Dies war aber für jetzt nicht der Zweck unserer Aufgabe, sondern diese bestand in einer möglichst einfachen und leicht und allgemein ausführbaren Methode. Ich glaube, diese einigermafsen erreicht zu haben, wenigstens werde ioh bestïnt in dieser Ansicht durch die Vergleichung der Producte, die durchaus zum Vortheil unserer Methode ausfallen; die Menge des Products endlich, welche dieselbe liefert, ist zwar etwas geringer, als die des nach der Pharmakopöe bereiteten Extractes, aber nur zum Vortheil, indem das 
nach anserer Methode dargestellte Extract reiner ist von fremden und unwirksamen Bestandtheilen als das letztere.

Es lieferte uns 1 Pfd. (à 16 Unzen) gepülvertes Bilsenkraut 3 Unzen 5 Drachmen, 1 Pfd. gepuilverter Belladonna 2 Unzen, 1 Pfd. gepülvertes Schierlingskraut 3 Unzen 2 Drachmen Extract.

Das Extract. Hyoscyami hatte eine gelblichbraune Farbe, einen sehr betäubenden, dabei etwas süfslichen Geruch, und löste sich in Wasser vollkommen klar auf, die Auflüsung war durchsichtig röthlichgelb, sie wurde durch Galläpfeltinctur stark getrübt, und nach einiger Zeit schieden sich viele gelbliche Flocken darin ab. In Alkohol löste sich das Extract.

Das Extractum Belladonnae war dunkclbraun ins Schwarzbraune, besafs den eigenthümlichen widrigen narkotischen Geruch der Pflanze im hohen Grade, dabei etwas tabacksartig; in Wasser löste es sich völlig auf, die Auflösung war dunkelbraun and wurde durch Galläpfeltinctur reichlich getrübt, die sich ausscheidenden Flocken besafsen eine schmutzig bräunlichgelbe Farbe. In Alkohol löste sich das Extract.

Das Extract. Conii hatte eine gelblichbraune Farbe, dem Extract. Hyoscyam. ganz gleich, einen intensiven narkotischen Geruch wie die Pflanze. Es löste sich in Wasser völlig und mit hellröthlichgelber Farbe auf, die Auflösung verhielt sich gegen Galläpfeltinctur wie das Bilsenkrautextract.

Als eine detaillirtere Erläuterung über den Werth dieser verschiedenen Methoden will ich folgende Versuche uiber das Extractum herbae Pulsatillae anfihhren.

a) $\frac{1}{2}$ Pfd. Herbae Pulsatillae sicc. wurde mit $2 \frac{1}{2}$ Pfd. Spirit. rectificat. einige Tage digerirt, darauf ansgeprefst und der Krantrürkstand mit 5 Pfd. kochendem Wasser Arch. d. Pharm. 11. Reihe. XXII. Bils. 1. Hft. 
übergossen, 24 Stunden stehen gelassen, und darauf ausgeprefst. Den wässrigen Auszug engte man bis auf ein Drittel ein und fällte denselben mit Weingeist, wozu ohngefähr das dreifache Volumen erforderlich war. Die von dem reichlichen Bodensatze abfiltrirte Flüssigkeit war nur nuch schwach gelblichbraun gefärbt, und wurde nach Vermischen mit dem ersten geistigen Auszuge der Destillation nnterworfen und nach weiterem Verdampfen 1 Unze 3 Drachmen eines grünlichbraunen Extractes erhalten, dieses entsprach, nach dem Resultate eines desfalls angestellten Versuchs, 415 Gran trocknem gepülverten Extracte.

b) $\frac{1}{2}$ Pfd. gröblich gepülvertes Kraut wurde im Cylinder mit Weingeist von 60 Proc. der Deplacirung unterworfen; zur völligen Erschöpfung dieses Krautes waren 3 Pfd. des gedachten Weingeistes erforderlich, der letzte Rückhalt des spirituösen Auszuges wurde durch etwas Wasser ausgetrieben. Es wurden erhalten 6 Drachmen eines schönen braunen Extractes, und 2: Drachmen Chlorophyll, welches nach dem Abdestilliren des Weingeistes sich ausgeschieden hatte; im Ganzen also 1 Unze $\frac{1}{2}$ Drachme Extract. Dieses zur Trockne gebracht, gab 370 Gran eines pulverförmigen Extractes, und mit Abzug dè Chlorophylls 259 Gran desselben. Nur dieses letztere kann als das reine Extract angesehen werden.

c) $\frac{1}{2}$ Pfd. des trocknen Krautes wurde mit 5 Pfd. kochendem Wasser übergossen, nach 24 Stunden ausgeprefst, und der Krautrückstand nochmals mit $2 \frac{1}{2}$ Pfd. kochendem Wasser auf gleiche Weise behandelt. Die colirten Auszüge lieferten nach Verdampfen 1 Unze 7 Drachmen Extract. Dieses Extract behandelte man mit 6 Unzen Spirit. rectificat,, und erhielt durch 
Verdampfen der Auflösung 6 Drachmen Extract, dieselbe Menge als durch Deplacirung; aber gewifs nicht so gut, es waren bei dieser Behandlung mehrtägige Digestionen und das Verdampfen von 7 Pfd. Wasser nöthig, bei der Deplacirung nur 3 Pfd. Spiritus. Es wurde hier absichtlich kein Alkohol, sondern nur Weingeist genommen, um das Resultat mit dem nach der Vorschrift der Pharmakopüe möglichst vergleichbar zu machen.

Nach einer sorgfältigen Kritik der belrannten verschiedenen Methoden zur Darstellung der narkotischen Extracte und der Producte, welche sie liefern, scheint mir der Vorzug der hier auseinandergesetzten, durch Deplacirung mit Alkohol etc., erwiesen; ich empfehle sie deshalb der besondern Aufmerksamkeit. Schliefslich bemerke ich noch, dafs die nach dieser Methode bereiteten Extracte nach anderthalbjähriger sorgsamer $\Lambda$ ufbewahrung, in Extractconsistenz, noch ihre ursprünglich schöne Beschaffenheit und den virösen Geruch der Pflanze im hohen Grade besitzen, und keine Spur von Schimmelbildung dabei wahrgenommen worden ist.

\section{Vierte Abtheilung.}

\section{Arzmeiformen und Compositionen.}

Ueber einige Syrupe mit Jodverbindungen; rom

Professor Dr. Tognio in Pesth.

\section{Syrupus Ferri jodati.}

Wacken roder's Abhandlung über dieses Präparat (diese Zeitschrift 2. R. Bd. XIX. S. 176.) interessirte mich so sehr, dafs ich diesen Syrup sofort in der 